\title{
HELEIETH SAFFIOTI NO COMPROMISSO DE TEORIZAÇÃO FEMINISTA: Entre a Academia, a Luta Feminista e as Organizações não governamentais (ONGs)
}

\author{
Raquel Lindôso* \\ Daniele Motta* *
}

\section{ENTREVISTA COM BETÂNIA ÁVILA ${ }^{1}$}

\begin{abstract}
Esta entrevista objetiva compreender o comprometimento de teorização feminista de Heleieth Saffioti através da análise da influência dessa autora para a academia, a luta feminista e as organizações não governamentais (ONGs). Para atender ao objetivo traçado, realizou-se uma visita à trajetória da intelectual feminista brasileira Betânia Ávila, como o exílio na França na década de 1970 e a criação do SOS Corpo - Instituto Feminista para a Democracia. Heleieth Safiotti marcou desde o início as teorizações feministas de Betânia Ávila, em particular os debates e conceituações sobre trabalho doméstico, patriarcado e práxis feminista.
\end{abstract}

Palavras-chave: Heleieth Saffioti. Teorização Feminista. Trabalho Doméstico. Patriarcado. Práxis Feminista.

\section{INTRODUÇÃO}

O diálogo com a intelectual feminista Betânia Ávila aconteceu na sede da organização feminista O SOS Corpo - Instituto Feminista para a Democracia, em dezembro de 2018, na cidade de Recife, capital do estado de Pernambuco, Brasil. A entrevistada, Betânia Ávila, é natural do estado de Alagoas e na capital pernambucana realizou a graduação e pós-graduação em Sociologia na Universidade Federal de Pernambuco (UFPE), com a pesquisa de doutoramento intitulada "O tempo do trabalho das empregadas domésticas: Tensões entre Dominação/Exploração e Resistência”. Publicada

\footnotetext{
* Universidade Estadual de Campinas (Unicamp). Rua Cora Coralina, 100 - Cidade Universitária. Cep: 130838960. Campinas - São Paulo - Brasil. raquel.lindoso@yahoo.com.br https://orcid.org/0000-0002-8657-3955

* * Instituto Federal de Educação, Ciência e Tecnologia de São Paulo (IFSP). Campus Capivari.

Avenida Doutor Ênio Pires de Camargo, 2971 - São João Batista. Cep: 13360-000. Capivari - São Paulo - Brasil. daniele.motta@ifsp.edu.br

https://orcid.org/0000-0002-7296-3688

${ }^{1}$ Durante a realização das entrevistas utilizamos gravador de voz e registro fotográfico. O termo de consentimento foi assinado em duas vias, e cópias foram entregues, conforme orientação do comitê de ética.
}

pela Editora Universitária e Programas de Pós-Graduação da UFPE (Ávila, 2009).

As elaborações políticas e sociais da entrevistada, bem como as pesquisas, traduções e publicações do SOS CORPO ${ }^{2}$ são muito relevantes para a formação de gerações de intelectuais (homens e mulheres), críticos e engajados, nos campos da sociologia do trabalho e da teoria feminista. A entrevista objetivou visitar a memória do movimento feminista brasileiro a partir da trajetória de exílio e formação política de Betânia Ávila e a criação do SOS CORPO, e, dessa forma, busca-se visibilizar as influências do pensamento de Heleieth Saffioti para a academia, a luta feminista e as organizações não governamentais (ONGs). Heleieth Safiotti marcou desde o início as teorizações do feminismo brasileiro e, consequentemente, a trajetória política de Betânia Ávila, em especial para os debates e conceituações sobre trabalho doméstico, patriarcado e práxis feminista.

${ }^{2}$ O SOS CORPO - Instituto Feminista para a Democracia é uma organizacão da sociedade civil, fundada no início da década de 1980, na cidade de Recife-PE. O SOS CORPO possui três grandes áreas de atuação, que são: educação, pesquisa e comunicação. O SOS CORPO possui, também, uma forte atuação na difusão e tradução da produção do pensamento feminista. Para mais informações acessar: http://soscorpo.org/ 
Por fim, gostaríamos de registrar o nosso agradecimento à Betânia Ávila e ao SOS Corpo que juntos ocupam um lugar central na difusão e reivindicação do legado de Heleieth Saffioti.

\section{ENTREVISTA}

Para iniciar, nós gostaríamos que você falasse da sua longa trajetória no movimento feminista, no SOS Corpo e os primeiros encontros com Saffioti.

Eu vivi em Paris nos anos de 1970 e lá participei do "Círculo de Mulheres Brasileiras em Paris". ${ }^{3}$ Esse círculo era constituído por brasileiras exiladas por causa das razões políticas daquela época ${ }^{4}$. Nesse período, consolidei minha militância e, a partir daí, definitivamente, minha formação acadêmica e de prática de trabalho é dedicada ao feminismo. No exílio acompanhávamos a imprensa feminista no Brasil através dos jornais "Nós Mulheres" e "Brasil Mulher", cujos profissionais eram enviados para Paris pela companheira Amelinha Teles ${ }^{6}$. Evidentemente, naquele período a comunicação era difícil, e receber material do Brasil levava tempo. Em um dos números do jornal "Brasil

${ }^{3} \mathrm{O}$ Círculo de Mulheres Brasileiras foi fundado em janeiro de 1976 em Paris por iniciativa de militantes de organizações de esquerda. Parte das mulheres que compunham o grupo eram exiladas políticas no Brasil. A intenção delas era debater a especificidade das mulheres com uma perspectiva socialista. Para maiores informações sobre Círculo de Mulheres Brasileiras em Paris indicamos a leitura de จิ Abreu (2014).

N ${ }^{4}$ Refere-se ao período da ditadura militar. No Brasil tal peฉे ríodo durou de 1964-1985 e foi marcado pela repressão e o violência a seus opositores. Muitas pessoas que se opuse\% ram ao regime foram exiladas para outros países fugindo ¿ da repressão política.

- em jornais Brasil Mulher e Nós Mulheres retrataram,

artigos e editoriais, a luta pela anistia, pelas cre-

ळ ches e pelas liberdades democráticas - todos símbolos da

m. oposiçẫo contra o regime no período da ditadura militar.

$\therefore$ Além disso, eles incluíam matérias específicas, tais como

Eิ violência doméstica, condições de trabalho das mulheres,

Tireitos reprodutivos, aborto e sexualidade" (Leite, 2003,

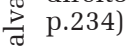

क ${ }^{6}$ Maria Amélia de Almeida Teles é militante feminista que foi presa e torturada durante a ditadura militar, vivendo o por anos na clandestinidade. Amelinha tem uma forte atuação na imprensa, sendo responsável pela edição dos jornais "Brasil Mulher" e "Nós Mulheres". Nós tivemos a honra de também entrevistar Amelinha Teles para tratar J da sua relação com Heleieth Saffioti.
Mulher" havia uma matéria sobre a publicação do livro "A Mulher na Sociedade de Classes: mito e realidade". Essa nota oportunizou a criação de uma conexão muito bonita entre Heleieth e as feministas no Brasil e no exílio.

Quando retornei ao Brasil, no final do nos anos de 1970, havia na cidade de Recife um grupo feminista chamado "Ação Mulher". Esse grupo político, formado por mulheres feministas radicais, lutava pelo direito à anistia. ${ }^{7}$ No agrupamento feminista "Ação Mulher" eu reencontrei algumas companheiras e, pouco tempo depois, juntas criamos o SOS CORPO - Insti-

tuto Feminista para a Democracia. Hoje o SOS Corpo tem trinta e oito anos. No SOS CORPO, eu atuo como pesquisadora e educadora popular. No início, nós sentimos a necessidade de construir uma biblioteca feminista, visto que o movimento começava a ter uma produção acadêmica e militante muito grande e potente. No entanto, com o passar do tempo, por causa do baixo orçamento, nós não conseguimos manter a biblioteca e atualizar todo o material. Daí nós decidimos abrir a linha de comunicação e, assim, o SOS Corpo permaneceu atuando na educação popular feminista, pesquisa e comunicação. O grupo sempre teve uma linha muito forte de edição, tanto é que a gente fazia isso de uma maneira não formalizada. Quero dizer, formalizada pela instituição a gente sempre fez, mas, hoje, a gente tem uma linha de trabalho chamada de "Edições Feministas". Essa linha de edições realiza publicações nossas e traduções e publicações de outras pesquisadoras.

O SOS Corpo assumiu a responsabilidade de trazer um pouco de outros pensamentos e abordagens feministas, já que o pensamento mais hegemonizado na universidade no campo do feminismo é o anglo-saxão, sobretudo, o norte americano. É bem verdade que atualmente as coisas estão um pouco mais expan-

\footnotetext{
${ }^{7}$ A luta pela anistia aos presos e perseguidos políticos durante a década de 1970 possui importante participação das mulheres, com o Movimento Feminino pela Anistia. Em 1978 foi criado o Comitê Brasileiro pela Anistia, e após ampla mobilização popular, em agosto de 1979 o então presidente João Figueiredo assina a Lei da Anistia, sendo concedido o "perdão" aos perseguidos políticos do regime militar
} 
didas, mas, de qualquer maneira, tanto a perspectiva latino-americana, quanto o feminismo materialista, são menos disponíveis.

Heleieth Saffioti foi uma pessoa que esteve ao lado SOS Corpo desde o início. Na verdade, o diálogo entre Heleieth e o movimento e organizações feministas é intenso desde os anos de 1980. E é nesse processo de diálogo permanente entre seu posicionamento teórico e sua participação política no movimento feminista, que se constrói uma triangulação muito importante entre luta feminista, universidade e organizações feministas. Heleieth reconhecia esses espaços políticos e de produção do conhecimento crítico e engajado. Em 1982, ela veio para Recife fazer uma conferência na Universidade Federal de Pernambuco, no departamento de Sociologia (CFCH/UFPE). Essa é uma memória muito forte para a gente, porque fomos incluídas na exposição e no diálogo de forma absolutamente memorável. Heleieth estava na mesa de exposição e sabia que as mulheres do SOS Corpo estavam ali para assistir à conferência, e surpreendeu todas e todos quando dedicou alguns minutos da palestra para apresentar o SOS Corpo. Essa apresentação foi realizada no sentido do reconhecimento, dizendo: "estão aí minhas companheiras do SOS Corpo". Heleieth sabia o que estávamos construindo; sabia que nós éramos um grupo de pensadoras, de intelectuais feministas, e naquela apresentação, legitimou, diante da comunidade acadêmica, o SOS Corpo como um espaço de produção de pensamento e análise social e política.

Nesse diálogo com o SOS Corpo, Heleieth veio para Recife diversas vezes. Em 2001, foi a conferencista e homenageada na grande celebração que fizemos na ocasião dos 20 anos. E o último retorno ao SOS Corpo e ao Recife, foi no ano de 2008, para uma conferência de final do ano, da qual saiu o texto que foi publicado em 2010 na revista "Cadernos de Crítica Feminista”, publicada em 2010. ${ }^{8}$ Um texto no qual

${ }^{8} \mathrm{O}$ texto citado pela interlocutora é: Quantos sexos? Quantos gêneros? Unissexo/Unigênero (Saffioti, 2009) publicado em dezembro de 2009. Todas as edições da revista "Cadernos da Crítica Feminista", organizada pelo instituto SOS ela, com inteligência, ousadia e capacidade de exercer o pensamento crítico lança questões contundentes dos tempos atuais. Para nós, esse foi um texto da despedida, de confirmação da sua obra, e da lembrança da sua presença querida e inspiradora.

Gostaríamos de conversar mais sobre a triangulação estabelecida entre Saffioti, luta feminista e academia. Como você pensa essa triangulação e quais são os principais desdobramentos?

Nesse sentido de pensar a triangulação - alguns aspectos são especialmente marcantes porque refletem os desdobramentos teóricos que são do pensamento de Heleieth e do campo do feminismo. O meu ponto de partida está nas questões relacionadas ao livro " $A$ Mulher na Sociedade de Classes: mito e realidade" (Saffioti, 2013 [1969]), e o feminismo. Eu penso o feminismo não a partir de ondas, mas como um movimento de transformação social e emancipação das mulheres, que é parte do movimento contraditório da história e, portanto, é parte das correlações de forças de cada contexto sócio histórico. O feminismo não é uma dinâmica separada que segue seu caminho a despeito de tudo; é um movimento social e um pensamento crítico. Portanto, para mim, é importante apreender essa obra seminal no seu contexto histórico e a sua produção de conhecimento como parte desse movimento histórico.

No momento do aparecimento do livro "A Mulher na Sociedade de Classes: mito e realidade" (ibidem), o contexto era a importância do marxismo e da teoria crítica no campo da esquerda e, do outro lado, a Ditadura Militar e seu sistema de controle, violência, repressão e perseguição política. O título desse livro pioneiro e fundamental já é, em si uma manifestação de um sujeito crítico que se confronta com o sistema político autoritário e, ao mesmo tempo, traz um confronto com o campo teórico no Corpo, estão disponíveis para acesso no endereço: https:// soscorpo.org/publicacoes/revista/ 
qual se insere os "Marxistas no Brasil". No título também é explicitada a dimensão materialista da sua elaboração, que implica no desvelamento da realidade social, não como aparência, mas como movimento do concreto, e evidentemente, a marcação do conceito de sociedade de classes. O feminismo faz a crítica ao sistema capitalista/patriarcal/racista/hetero-normativo e, também, à teoria crítica que não considerou as mulheres como sujeito histórico, nem como sujeito de conhecimento e do trabalho e, assim, desconsiderou as relações sociais de sexo/ gênero e suas imbricações com as de classe e de raça. Essa crítica realizada através de uma prática dialógica se estende a todas as matrizes teóricas mesmo que seja sempre possível, para uma análise feminista, resgatar uma maior aproximação ou mesmo se situar dentro de uma ou outra corrente. A teoria marxista tem sido, desde o início, uma referência e uma inspiração metodológica para as correntes feministas que desenvolveram e desenvolvem teorias no campo do materialismo histórico. Se "insurgir" através do diálogo crítico contra o corpus teórico dominante nas ciências sociais, em qualquer uma de suas perspectivas, foi e continua sendo para o feminismo uma das grandes tarefas da sua práxis. E essa tarefa Heleieth realizou durante todo o seu percurso de elaboração e participação política, ao trazer as relações de classe entre mulheres, desnaturalizando o conceito de mulher como uma condição e como um grupo จ homogêneo. As relações sociais estão lá e esసิ truturam seu pensamento mesmo que, naquele momento histórico da segunda metade da décađa de 1960, não chegue às relações de gênero, i ou relações sociais de sexo, enquanto conceito, ¿. mas anunciam a perspectiva da determinação ले de sexo para tratar das relações de opressão. Heleieth faz o seu primeiro exercício de criação crítica sobre as mulheres a partir de uma perspectiva materialista histórica e, talvez, o primeiro exercício de reflexão que sinaliza para a questão de raça e patriarcalismo na formação social brasileira. E posteriormente, a questão do Nó das relações sociais de classe, raça e gênero.
De que maneira você analisa o foco dado por Saffioti para o trabalho doméstico? Há uma relação com as elaborações anteriores como a formação social brasileira e a trajetória escravocrata e o patriarcalismo?

A análise a partir da construção do sumário do livro "A Mulher na Sociedade de Classes: mito e realidade" (Op. cit.) traz sinalizações muito interessantes para pensar essa questão. O sumário trata da inserção do Brasil no contexto da economia capitalista mundial e as relações de poder e desigualdade entre países do Norte e do Sul - aqui situo a questão da colonialidade - e, na sequência, a dimensão subjetiva a partir da crítica a Freud e à questão de classe. É interessante, inclusive, porque na Europa e, por aqui também, a imagem e experiência da mulher vitoriana foram muito universalizadas. Hoje, esta questão da diversidade da experiência de ser mulher está colocada, mas Heleieth sinaliza essa necessidade de pluralidade já em 1969.

A pesquisa empírica sobre as mulheres trabalhadoras traz a base concreta para pensar esta experiência social de mulheres situadas em contextos concretos. A teorização produz dois desdobramentos importantes. O primeiro é a análise do trabalho doméstico, em sua diferenciação entre Norte e Sul global. No Norte global o trabalho doméstico é gratuito, enquanto no Sul, o trabalho doméstico é um processo inextricável da contradição no interior da categoria mulheres, e sendo assim, o trabalho doméstico é gratuito e remunerado. Nessa análise que Saffioti (1979) realiza, é evidenciada a importância crucial do trabalho doméstico para pensar a formação social brasileira e a relação entre classe, raça e gênero, como relação social ou, relações sociais de sexo.

O segundo desdobramento é a investigação que parte da concepção de "exército industrial de reserva”. Há também, em sua análise, uma indicação para a necessidade de repensar esse conceito e o chamado evidencia a sua compreensão, de acordo com o materialismo, 
das particularidades dos contextos sócio-históricos para a análise crítica do sistema capitalista. O pressuposto teórico que constitui a base do estudo em questão é aquele que considera essa coexistência como dinâmica e integrada, de acordo com os interesses e necessidades do setor capitalista da economia. Para Saffioti, os trabalhadores dos setores não capitalistas estão à margem do modo de produção capitalista, mas, por outro lado, estão integrados no sistema capitalista e permitem a este alcançar uma taxa mais elevada de acumulação, na medida em que realizam tarefas necessárias à reprodução ampliada do capital.

Para mim essa reflexão é atual, já que ajuda na compreensão dos meios usuais para alcançar taxas cada vez mais elevadas de acumulação, com a reestruturação das relações de trabalho globalmente, e os processos de desapossamento. Além disso, em nossa pesquisa sobre as trabalhadoras em trabalhos precários em Barcarena, Pernambuco e São Paulo, ${ }^{9}$ uma dimensão da precariedade é justamente a intermitência de inserção, que também me remeteu a essa questão de Saffioti. Mas do ponto de vista das mulheres, o trabalho doméstico, as habilidades para isso forjadas como parte do aprendizado na vida cotidiana e doméstica, desde a infância funcionam como uma reserva de possibilidades estratégicas de conseguir uma renda, quando nos períodos de desemprego em outros setores.

E como você compreende o patriarcado nas análises no pensamento de Saffioti? Qual a relação do patriarcado com os estudos do trabalho?

A conceituação do patriarcado é outro desdobramento fundamental da reflexão informada na triangulação. A partir dos anos 1960 e 1970, em diversos países, o patriarcado é tomado como questão central da teorização feminista. E essa busca do debate a respeito

${ }^{9}$ A pesquisa encontra-se disponível em: http://soscorpo. org/areas-de-trabalho/pesquisa/autonomiamulheres/Desenvolvimento-Trabalho-e-Autonomia\%20Economica.pdf do patriarcalismo faz parte inclusive do compromisso feminista com a teorização. E nós sabemos que as elaborações travadas no bojo do feminismo são fortemente atacadas. O conceito de patriarcado é atacado por supostamente ser mítico e universalista, quando, na verdade, o patriarcado serve até hoje como referência política e sustentação de um discurso político, mesmo que sua elaboração ainda esteja em construção.

O Brasil carece muito de elaborações teóricas que partam da sua própria realidade. Até hoje, quando o feminismo fala em patriarcado, muitas vezes a academia traduz em patriarca e/ ou pai biológico. Ou seja, muitas incompreensões e ausências de formulações, e essas traduções mantem a falta de uma formulação mais robusta. O conceito de patriarcado, analisado do ponto de vista sociológico e antropológico, é uma contribuição da teorização feminista. Não é à toa que no feminismo francês radical 10 - que não é o mesmo que o radical americano - o conceito central é o patriarcado, constitutivo do próprio desenvolvimento da práxis feminista.

No contexto neoliberal, os conceitos mais radicais e críticos que dão conta dos processos contraditórios, foram e são sistematicamente banidos da Universidade. O apagamento do patriarcado como conceito chave do feminismo, é um exemplo muito forte da tentativa de estabelecer uma prática feminista mais conciliatória. Heleieth faz uma teorização contra a maré, já que no seu pensamento patriarcado é compreendido enquanto um sistema e o gênero como relações sociais. Ela afirma, inclusive, que essas relações de gênero se expressam no contexto histórico desse sistema Capitalista e Patriarcal. Isso é ainda mais relevante porque no surgimento e expansão do uso do conceito de gênero, muitas feministas - teóricas e militantes - trataram patriarcado e gênero como termos substituíveis. Quando,

${ }^{10}$ A socióloga feminista Christine Delphy é uma das intelectuais importantes dessa concepção do feminismo radical franceses. 
na verdade, patriarcado se refere ao sistema e gênero a relações sociais que conformam este sistema na imbricação com outras relações sociais de classe e raça.

Para o feminismo materialista, já nos anos de 1970, a questão do trabalho é muito forte e é daí que vem a reflexão da divisão sexual do trabalho e do trabalho doméstico. No entanto, a experiência francesa e européia de trabalho doméstico, na época, era discutida a partir da análise do trabalho doméstico geral, ou seja, não se tratava a questão do trabalho doméstico remunerado. Esse foco no trabalho doméstico geral tem a ver com as condições sociopolíticas daquela época e, também, com o contexto francês. No Brasil, a questão se apresenta totalmente diferente em termos sociais, políticos e econômicos, já que o trabalho doméstico é muito forte tanto em termos de importância estrutural, quanto para as análises feministas. O debate do patriarcado é contemporâneo das reflexões sobre o trabalho doméstico.

Em 1980, a primeira organização de pesquisa na qual estive envolvida, antes mesmo da criação do SOS Corpo, ainda no agrupamento "Ação Mulher", foi formalmente fundada em diálogo com o Sindicato das Trabalhadoras Domésticas (Sindomestica - Recife). Essa pesquisa objetivou produzir dados e análises que apoiassem nossa elaboração do trabalho doméstico e, também, as discussões que o i sindicato realizava naquela época. Então, essa ลे organização em torno do trabalho doméstico क्ञ precede a própria formalização do SOS Corpo. E a partir daí, estabeleceu-se uma relação política muito profunda e, também, de reflexão e $\dot{2}$ análise com o Sindicato.

लొ A elaboração da questão do Trabalho foi uma referência bibliográfica para nós, inclusive, porque Saffioti trazia nas suas análises a questão do patriarcado, que é um tema muito caro para nós desde o início. No agrupamento "Ação Mulher", nós tínhamos uma análise com ênfase no patriarcado, visto que o Nordeste é um contexto social, econômico e po- lítico fortemente marcado pelo mesmo. E por isso, nós precisávamos problematizá-lo, além de outros conceitos de desigualdade social e de classe. Mas no âmago dessas elaborações, nós mantivemos a referência do patriarcado e do trabalho, mesmo quando o gênero ganhou força e foi apresentado como substitutivo do patriarcado.

O debate sobre este e o trabalho, assim como o diálogo com Heleieth, estão muito presentes na minha trajetória pessoal, e também, na trajetória do SOS Corpo, por causa da confluência interna do próprio coletivo e das suas ligações externas, políticas e reflexivas. No meu ponto de vista, a trajetória de Saffioti é de abrir campos temáticos de pesquisa, reflexões e referências teóricas, sem perder sua elaboração crítica e materialista. Esse é um campo de pensamento da realidade social material, simbólica e contextualizada e, também, é um caminho epistêmico e militante de muita resistência.

Recebido para publicação em 20 de julho de 2020 Aceito em 20 de novembro de 2020

\section{REFERÊNCIAS}

ABREU, Maira Luisa. Feminismo no exílio: o Círculo de Mulheres Brasileiras em Paris e o Grupo Latino-Americano de Mulheres. São Paulo, Alameda, 2014.

ÁVILA, Maria Betânia. O tempo do trabalho das empregadas domésticas: tensões entre dominacão/ exploração e resistência. Recife: Editora da Universidade Federal de Pernambuco, 2009.

LEITE, Rosalina de Santa Cruz. Brasil Mulher e Nós Mulheres: origens da imprensa feminista brasileira. Revista de Estudos Feministas, Florianópolis, 11(1): 336, jan-jun/2003, p.234-241.

SAFFIOTI, Heleieth. A mulher na sociedade de classes: mito e realidade. Heleieth Saffioti. 3a edição. São Paulo: Editora expressão popular, 2013 [1969].

limitada, Rio de Janeiro, 1979.

. Emprego doméstico e capitalismo. Avenir editora . Quantos sexos? Quantos gêneros? Unissexo/ Unigênero? Cadernos de Crítica Feminista, Ano III, N. 2, Recife, 2009, p.6-32. 


\section{HELEIETH SAFFIOTI IN THE FEMINIST THEORIZATION COMMITMENT: between academia, feminist movement and non- governmental organizations (ONGs)}

\author{
Raquel Lindôso \\ Daniele Motta
}

This interview aims to understand Heleieth Saffioti's commitment to feminist theorization through the analysis of the influence of this author for the university, feminist movement and nongovernmental organizations (ONGs). To meet the objective set, we paid a visit to the trajectory of the Brazilian feminist intellectual Betânia Ávila, as the exile in France in the 1970s and the creation of SOS Corpo - Feminist Institute for Democracy. Heleieth Safiotti marked Betânia Ávila's feminist theories from the beginning, in particular the debates and concepts about domestic work, patriarchy and feminist praxis.

Keywords: Heleieth Saffioti. Feminist Theory. Household Work. Patriarchy. Feminist Praxis.

\section{L'ENGAGEMENT D'HELEIETH SAFFIOTI: entre l'université, la lutte féministe et les organisations non gouvernementales}

\author{
Raquel Lindôso \\ Daniele Motta
}

Cette entretien vise à comprendre l'engagement d'Heleieth Saffioti dans la théorisation féministe. Ces dernières ont pris forme dans le croisement entre le monde universitaire, la lutte féministe et les organisations non gouvernementales (ONGs). Nous sommes parties de la trajectoire de l'intellectuelle féministe brésilienne Betânia Ávila - notamment son exil en France dans les années 1970 et la création de SOS Corps - Institut féministe pour la démocratie pour comprendre l'importance de Saffioti pour le féminisme brésilien. Heleieth Safiotti a marqué dès le début les théorisations de Betânia Ávila, notamment les débats et les conceptualisations du travail domestique, du patriarcat et de la praxis féministe.

Mots CLÉs: Heleieth Saffioti. Théorisation féministe. Travail domestique. Patriarcat. Praxis féministe. 
